\title{
Development and Testing of a Bubble Positive Airway Pressure System: Why Didn't I Think of That?
}

Worldwide, about 1 million infants die each year from respiratory causes. In resource-limited settings, as many as one third of these deaths are probably preventable. ${ }^{1}$ Preterm birth is the most common cause of perinatal mortality, causing almost $30 \%$ of neonatal deaths, and respiratory distress syndrome is the leading cause of death in preterm infants, affecting roughly $1 \%$ of all newborns worldwide. The first day of life is the most critical period for at-risk infants, ${ }^{2}$ and three fourths of neonatal deaths occur in the first week of life. ${ }^{3}$ Tragically, many of these infants die due to a lack of access to basic medical care and respiratory support devices like CPAP and infant ventilators.

In resource-limited countries, use of bubble CPAP decreases the need for mechanical ventilation and improves survival. ${ }^{4,5}$ Further, use of a low-cost bubble CPAP device is cost-effective when compared with the use of nasal cannula. ${ }^{6}$ Although nasal cannula is roughly half the cost of bubble CPAP, the use of bubble CPAP resulted in an incremental cost-effectiveness of 6.78 life-years over that of nasal cannula. ${ }^{6}$ Bubble $\mathrm{CPAP}$, therefore, is a noninvasive, inexpensive means of providing respiratory support and of improving survival in vulnerable newborns. Unfortunately, although bubble CPAP is often helpful, a subset of infants still require more respiratory support than bubble CPAP can provide, and cheap, reliable, and easy-to-maintain devices are needed to fill this void in resource-limited settings. ${ }^{1}$ If effective, any such device could potentially save thousands of lives.

In this issue of RESPIRATORY CARE, John et $\mathrm{al}^{7}$ describe one possible approach to this vexing issue. In "Development and Testing of a Bubble Bi-Level Positive Airway Pressure System," they present their conceptualization, design, and testing of a novel respiratory technology for use in resource-limited settings. The concept is reasonably simple, can be used to modify existing bubble CPAP devices, and, by extension, may be a relatively inexpensive solution to a big problem in resource-limited settings. Specifically, the authors describe a novel bi-level PAP device,

\footnotetext{
The authors have disclosed no conflicts of interest.
}

Correspondence: Edward G Shepherd MD, Nationwide Children's Hospital, The Ohio State University College of Medicine, 700 Children's Drive, Columbus, $\mathrm{OH}$ 43205. E-mail: edward.shepherd@nationwidechildrens.org.

DOI: $10.4187 /$ respcare. 05800 which uses a standard bubble CPAP system that is modified to provide 2 levels of positive airway pressure. The 2 pressure levels are delivered via a time-cycled, pressurelimited delivery system that requires no additional power

See the Original Study on Page 1131

or advanced technology relative to bubble CPAP. The device has 2 openings for the release of pressure at 2 separate levels within a submerged bubble CPAP tube. A basket entrains air from the bubble CPAP system and is attached to the tubing by a sleeve. Gas bubbles enter the circuit and accumulate in the basket, and the buoyant force of the entrained gas causes the basket to rise vertically along the submerged pipe, alternately occluding the proximal and distal openings. The depth of each opening in the water determines the pressure delivered; an opening that is $5 \mathrm{~cm}$ below the surface delivers $5 \mathrm{~cm} \mathrm{H}_{2} \mathrm{O}$, one that is $8 \mathrm{~cm}$ below the surface delivers $8 \mathrm{~cm} \mathrm{H}_{2} \mathrm{O}$, and so on. As gas bubbles accumulate, the basket rises to the upper position, where the device then occludes the holes so that no additional bubbles are released from the bubble CPAP system, simultaneously venting the gas entrained in the basket. The basket then loses buoyancy and drops along the tubing shaft, restarting the cycle by opening the upper hole through which pressurized gas can enter the system. Pressures are set by the relative depth of the exhaust holes, and the cycle time is adjusted by an in-line needle valve that adjusts the air flow to the device. The higher the air flow, the faster the cycle.

The critical, potential innovation described here is the ability to provide significantly greater levels of respiratory support to vulnerable infants at very little incremental cost relative to bubble CPAP. In principal, the amount of pressure potentially deliverable by this device is limited only by the depth of the water. Indeed, if the results described in this model are found to be applicable within a real-life setting on real infants, the pressures achievable using this device may be similar to those of mechanical ventilators (although there is no way for these to be synchronized to the baby's respiratory effort).

Although these results are exciting, they are preliminary. Specifically, the authors tested this device in intubated mannikins to demonstrate the feasibility and 
reliability of delivering a high pressure of either 8 or 15 $\mathrm{cm} \mathrm{H}_{2} \mathrm{O}$ and a low pressure of $5 \mathrm{~cm} \mathrm{H}_{2} \mathrm{O}$ for a period of $48 \mathrm{~h}$. They report that the device was indeed reliable at delivering alternating levels of PAP at a rate of 30-45 cycles/min and sustainable with little maintenance required other than ensuring that the water level remained optimal. Indeed, the device was compared with existing high-tech bilevel PAP and noninvasive ventilation devices, and it was able to match pressure targets within an SD of less than $10 \%$. The authors acknowledge the limits of the study, especially the use of a closed system through an endotracheal tube, which does not necessarily mimic an in vivo noninvasive CPAP system. The authors therefore consider this a first step in device development and fully acknowledge that additional testing and study of this novel system are necessary.

The authors describe here a potentially life-saving technology for infants in resource-limited settings, demonstrating the efficacy of the device in both term and pre-term mannikins. The device is extraordinary as much for its simplicity as for its novelty. The authors have provided a rational solution to a problem with global implications. If perfected and confirmed in real-world situations, the device has real potential to save lives in resource-limited settings. We look forward to the full development of this device, and to future iterations!

\section{J Wells Logan MD \\ Edward G Shepherd MD}

Neonatology

Nationwide Children's Hospital

The Ohio State University

Columbus, Ohio

\section{REFERENCES}

1. Lawn JE, Cousens S, Zupan J. 4 million neonatal deaths: when? Where? Why? Lancet 2005;365(9462):891-900.

2. Baqui AH, Darmstadt GL, Williams EK, Kumar V, Kiran TU, Panwar $D$, et al. Rates, timing and causes of neonatal deaths in rural India: implications for neonatal health programmes. Bull World Health Org 2006;84(9):706-713.

3. Lawn JE, Kinney M. Preterm birth: now the leading cause of child death worldwide. Sci Transl Med 2014;6(263):263ed221. doi: 10.1126/ scitranslmed.aaa2563.

4. Martin S, Duke T, Davis P. Efficacy and safety of bubble CPAP in neonatal care in low and middle income countries: a systematic review. Arch Dis Child Fetal Neonatal Ed 2014;99(6):F495-F504.

5. Kawaza K, Machen HE, Brown J, Mwanza Z, Iniguez S, Gest A, et al. Efficacy of a low-cost bubble CPAP system in treatment of respiratory distress in a neonatal ward in Malawi. PLoS One 2014;9(1):e86327.

6. Chen A, Deshmukh AA, Richards-Kortum R, Molyneux E, Kawaza K, Cantor SB. Cost-effectiveness analysis of a low-cost bubble CPAP device in providing ventilatory support for neonates in Malawi: a preliminary report. BMC Pediatr 2014(Can't get issue from record); 14:288.

7. John S, Barnett JD, Habben ND, Le HT, Cheng E, John SP, Gustafson SP. Development and testing of a bubble bi-level positive airway pressure system. Respir Care 2017;62(9):1131-1136. 